\title{
Atrial Natriuretic Peptide Attenuates the Development of Pulmonary Hypertension in Rats Adapted to Chronic Hypoxia
}

\author{
Hongkui Jin, Ren-Hui Yang, Yiu-Fai Chen, Robert M. Jackson, and Suzanne Oparil \\ Hypertension Program of the Division of Cardiovascular Disease and Division of Pulmonary and Critical Care Medicine, \\ Department of Medicine, University of Alabama at Birmingham, Birmingham, Alabama 35294
}

\begin{abstract}
To test the hypothesis that chronic infusion of atrial natriuretic peptide (ANP) instituted before hypoxic exposure attenuates the development of pulmonary hypertension in hypoxia adapted rats, ANP (0.2 and $1.0 \mu \mathrm{g} / \mathrm{h})$ or vehicle was administered intravenously via osmotic minipump for 4 wk beginning before exposure to $10 \% \mathrm{O}_{2}$ or to room air. Low dose ANP increased plasma ANP levels by only $60 \%$ of vehicle controls after $4 \mathrm{wk}$ and significantly decreased mean pulmonary arterial pressure (MPAP) $(P<0.01)$, the ratio of right ventricular weight to body weight $(\mathrm{RV} / \mathrm{BW})(P<0.01)$, and the wall thickness of small $(50-100 \mu \mathrm{m})$ pulmonary arteries $(P=0.01)$ in hypoxia-adapted rats. ANP did not alter any of these parameters in air-control rats. High dose ANP increased plasma ANP levels by $230 \%$ of control and produced greater reductions in MPAP $(P<0.001)$ and RV/BW $(P<0.05)$, but not in pulmonary arterial wall thickness, than the low dose. Neither dose of ANP altered mean systemic arterial pressure in either hypoxic or normoxic rats. The data demonstrate that chronic infusion of exogenous ANP at a dose that does not affect MPAP or RV weight in air-control rats attenuates the development of pulmonary hypertension and RV enlargement in rats adapted to chronic hypoxia. (J. Clin. Invest. 1990. 85:115-120.) atrial natriuretic peptide $\bullet$ chronic hypoxia $\bullet$ pulmonary circulation $\cdot$ pulmonary hypertension $\bullet$ rats
\end{abstract}

\section{Introduction}

Preliminary evidence suggests that atrial natriuretic peptide (ANP) ${ }^{1}$ may play a role in regulating pulmonary vascular tone (1-4) and may be involved in the pathogenesis of hypoxia-induced pulmonary hypertension $(5,6)$. Acute hypoxia stimulates the release of ANP from isolated rat and rabbit hearts (6) and increases circulating ANP levels in anesthetized rabbits (5) and pigs (7). Increased plasma ANP levels have been found in rats exposed to chronic hypoxia (8) and in patients with chronic pulmonary hypertension (9). Specific binding sites for ANP have been demonstrated in the lung $(10,11)$, and ANP is

Address reprint requests to Dr. Hongkui Jin, 1024 Zeigler Research Bldg., University of Alabama at Birmingham, UAB Station, Birmingham, AL 35294.

Received for publication 10 January 1989 and in revised form 22 August 1989.

1. Abbreviations used in this paper: ANP, atrial natriuretic peptide; BW, body weight; $L V+S$, left ventricle and septum; MPAP, mean pulmonary arterial pressure; MSAP, mean systemic arterial pressure; RV, right ventricular free wall.

J. Clin. Invest.

(C) The American Society for Clinical Investigation, Inc.

0021-9738/90/01/0115/06 \$2.00

Volume 85, January 1990, 115-120 taken up during its passage through the pulmonary circulation (12). Some evidence suggests that ANP has a direct effect on the pulmonary vasculature, causing relaxation of isolated segments of pulmonary artery from the guinea pig, pig, and man in vitro $(1,2)$. Further, data have been presented that demonstrate that intravenous administration of ANP blunts the pulmonary arterial vasoconstriction induced by acute hypoxia in conscious rats (13) and in anesthesized cats (14), dogs (15), and pigs (7).

Our previous studies (16) demonstrated that ANP reduces pulmonary artery pressure in the rat in vivo, and that this effect is greater in the hypoxia-adapted animals than in air controls. Experiments using the isolated-buffer-perfused lung further demonstrated that the pulmonary depressor effect of ANP in hypoxic rats is due to direct dilation of the pulmonary vasculature (16). The current study tested the hypothesis that chronic infusion of ANP begun before initiation of hypoxic exposure attenuates the development of pulmonary hypertension in hypoxia-adapted rats. Our results demonstrate that chronic infusion of ANP produces a dose-related attenuation in the development of pulmonary hypertension and right ventricular hypertrophy in hypoxia-adapted rats but does not alter either parameter in air controls.

\section{Methods}

Male Sprague-Dawley rats were obtained from Charles River Breeding Laboratories, Inc. (Wilmington, MA) at 8 wk of age. Osmotic minipumps (2002 mini-osmotic pump; Alza Corp., Palo Alto, CA) filled with either ANP (1-28, rat; Bachem, Inc., Torrance, CA) to deliver a dose of 0.2 or $1.0 \mu \mathrm{g} / \mathrm{h}$ in $0.1 \mathrm{M}$ acetic acid or the $0.1 \mathrm{M}$-acetic acid vehicle were implanted in the right jugular vein under ether anesthesia. After recovery from ether, rats were maintained in $10 \% \mathrm{O}_{2}$ at ambient pressure as previously described (17). Age-matched rats were maintained in filtered room air as normoxic controls. Five groups of rats were studied: normoxic + vehicle $(n=14)$, normoxic + ANP $(0.2$ $\mu \mathrm{g} / \mathrm{h})(n=8)$, hypoxic + vehicle $(n=17)$, hypoxic $+\operatorname{ANP}(0.2 \mu \mathrm{g} / \mathrm{h})(n$ $=9)$, and hypoxic $+\operatorname{ANP}(1.0 \mu \mathrm{g} / \mathrm{h})(n=7)$.

Rats were exposed to hypoxia in a 330-liter plexiglas glove box (Manostat, Brooklyn, NY). Hypoxic exposures (range 10.0 $\pm 0.5 \% \mathrm{O}_{2}$ ), were accomplished by adding $\mathrm{N}_{2}$ (Southern Welding, Birmingham, $\mathrm{AL}$ ) to the chamber intermittently from a liquid $\mathrm{N}_{2}$ reservoir, the gas outflow of which was controlled by a solenoid valve activated by the recorder output of an S3-A $\mathrm{O}_{2}$ analyzer (Applied Electrochemistry, Sunnyvale, CA) through a control circuit (model 371-K; LFE Corp., Clinton, MA). A baralyme (Allied Health Care Products, St. Louis, MO) $\mathrm{CO}_{2}$ scrubber kept the $\left[\mathrm{CO}_{2}\right]$ at $<0.2 \%$. Relative humidity within the chamber was kept at $<70 \%$ with anhydrous $\mathrm{CaSO}_{4}$. Boric acid was used to keep $\mathrm{NH}_{3}$ levels within the chamber at a minimum. Animals were permitted to have standard laboratory chow and tap water ad lib. Daily animal maintenance was carried out without interruption of the exposures. 2 wk later, the minipumps were exchanged under ether anesthesia.

After intravenous infusion of either ANP or vehicle, and exposure to hypoxia or room air for a total of $4 \mathrm{wk}$, rats were anesthetized with 
pentobarbital sodium ( $50 \mathrm{mg} / \mathrm{kg}$, i.p.). The trachea was cannulated and the rats were artificially ventilated with a rodent respirator (Harvard Apparatus Co., S. Natick, MA; tidal vol., $1 \mathrm{ml} / 100 \mathrm{~g}$ body wt.; rate, 60 $\min ^{-1}$ ). Catheters (PE-10 fused to PE-50) filled with heparin-saline solution $(50 \mu \mathrm{m} / \mathrm{ml})$ were implanted into the abdominal aorta through the right femoral artery for measurement of systemic arterial pressure. A thoractomy was performed, and a similar catheter was inserted into the pulmonary artery through the outflow tract of the right ventricle. The exposed chest was closed with wound clips and sutured. Mean systemic and pulmonary artery pressures were monitored simultaneously through the femoral and pulmonary arterial catheters. After a 30-min period of stabilization, mean systemic arterial pressure (MSAP) and mean pulmonary arterial pressure (MPAP) were recorded. Then, blood $(1.5 \mathrm{ml})$ was collected from the femoral arterial catheter for plasma ANP measurement. Plasma was immediately separated by centrifugation at $4^{\circ} \mathrm{C}$ and stored at $-80^{\circ} \mathrm{C}$ until RIA for ANP.

The spent minipumps were removed and weighed in order to confirm that they were delivering their contents properly and that the infusate had not run out completely. The infusate samples were stored at $-80^{\circ} \mathrm{C}$ until RIA for ANP. To determine the time course of plasma ANP levels during intravenous infusion of exogenous peptide, minipumps containing ANP $(0.2 \mu \mathrm{g} / \mathrm{h})$ were implanted into the right jugular vein, and catheters were placed in the right femoral artery as previously described in two age-matched air-control rats. Blood $(1 \mathrm{ml})$ was collected from the arterial catheter of conscious rats for ANP measurement $1,3,7,10$, and $14 \mathrm{~d}$ after minipump implantation. An equal volume of saline was infused to replace the blood loss.

We carried out an additional pilot study to determine the stability of ANP in $0.1 \mathrm{M}$ acetic acid at body temperature in vitro. ANP was dissolved in $0.1 \mathrm{M}$ acetic acid at a final concentration of $0.44 \mu \mathrm{g} / \mu \mathrm{l}$, the same as that injected into minipumps for chronic infusion. The ANP solution was placed in a vacuum oven at $37^{\circ} \mathrm{C}$, and aliquots $(50 \mu \mathrm{l})$ were removed after $1,2,3,4,5,6,8,10,12$, and $14 \mathrm{~d}$ and stored at $-80^{\circ} \mathrm{C}$ before ANP measurement.

After removal of blood for ANP assay, the thorax was opened, the left atrium was tied off, a tracheal cannula was inserted, and another cannula was placed in the pulmonary trunk. The lungs were fixed in the distended state by simultaneous infusion of $10 \%$ buffered formalin into the pulmonary artery and trachea at 100 and $25 \mathrm{~cm} \mathrm{H}_{2} \mathrm{O}$ pressure, respectively. The cannulas were clamped, and the entire specimen was placed in a bath of $10 \%$ buffered formalin for $24 \mathrm{~h}$. Blocks $5-\mathrm{mm}$ thick were taken from the right lower lobe at two-thirds of the distance from the hilum to the pleural surface along the bronchial axis. Sections $5-\mu \mathrm{m}$ thick were cut for light microscopy, and stained with hematoxylin eosin and Masson trichrome. For each rat, the wall thickness and vessel diameter of at least 25 consecutive arteries (range 50-100 $\mu \mathrm{m}$ ) were determined at 450 magnification, using a computerized morphometric system (Biaquant, Nashville, TN) in order to assess the pulmonary vascular effects of the ANP infusion. For statistical analysis, the wall thickness of each artery was expressed as a percent of vessel diameter according to the formula (18): \% wall thickness $=2 \mathrm{x}$ medial wall thickness/external diameter $\times 100$. Finally, the heart was removed and the atria and major vessels were dissected off by a circular incision. The right ventricular free wall (RV) was dissected from the left ventricle and septum $(\mathrm{LV}+\mathrm{S}) . \mathrm{RV}$ and $\mathrm{LV}+\mathrm{S}$ were weighed immediately. The ratio $R V / L V+S$ was used as an index of the effect of the ANP infusion on pulmonary hypertension in the hypoxic animals.

ANP concentration in plasma or $0.1 \mathrm{M}$ acetic acid measured by a modification of the RIA of Tanaka et al. (19) and Eskay et al. (20). Plasma for ANP determination was extracted with Sep-Pak C-18 cartridges (Waters Associates, Milford, MA) by the method of Eskay et al. (20). Extracts were dried under vacuum and reconstituted in RIA buffer (see below). Rat 8-33 ANP (Peninsula Laboratories, Inc., Belmont, CA) was used as the reference standard. Rabbit anti-rat $\alpha$ ANP antiserum was generously donated by Wyeth Laboratories (Philadelphia, PA). During the assay, $10 \mu$ of standard $(2-250 \mathrm{pg})$ or sample were incubated for $48 \mathrm{~h}$ at $4^{\circ} \mathrm{C}$ with $100 \mu \mathrm{l}(8,000 \mathrm{cpm})$ of ${ }^{125} \mathrm{I}$-labeled rat ANP (DuPont/New England Nuclear Research Products, Boston,
MA), $100 \mu \mathrm{l}$ of ANP antiserum and $200 \mu \mathrm{l}$ RIA buffer ( $50 \mathrm{mM}$ potassium phosphate buffer, pH 7.4, containing $0.1 \% \mathrm{BSA}, 0.01 \% \mathrm{NaN}_{3}$, $0.1 \%$ Triton X-100, $50 \mu \mathrm{M}$ PMSF, $50 \mathrm{mM} \mathrm{NaCl}$ and $0.0005 \%$ aprotinin). Separation of bound from free tracer was done by adding $750 \mu \mathrm{l}$ of $20 \%$ polyethylene glycol- 8000 and $75 \mu \mathrm{l}$ of $1.5 \%$ bovine gamma globulin to each assay tube and centrifuging for $1 \mathrm{~h}$ at $2,200 \mathrm{~g}$ (21). Recovery of ANP from plasma, as assessed by addition of unlabeled 8-33 ANP to normal rat plasma, was $91 \pm 4 \%$. Nonspecific binding of the tracer was $3 \%$. The sensitivity of the ANP-RIA was $3.3 \mathrm{pg} /$ assay tube, with $50 \%$ displacement at $33 \mathrm{pg} /$ assay tube.

Statistical analysis. Data are expressed as mean \pm SE. One-way analysis of variance was used to compare values for each parameter among normoxic + vehicle, normoxic + ANP $(0.2 \mu \mathrm{g} / \mathrm{h})$, hypoxic + vehicle, hypoxic + ANP $(0.2 \mu \mathrm{g} / \mathrm{h})$, and hypoxic + ANP $(1 \mu \mathrm{g} / \mathrm{h})$ groups. $P<0.05$ was considered significant.

\section{Results}

Rats exposed to hypoxia for 4 wk had significantly greater MPAP than air controls $(33.9 \pm 0.6 \mathrm{mmHg}$ vs. $17.1 \pm 0.5$ $\mathrm{mmHg}, P<0.001$ ) (Fig. 1, top). Chronic ANP infusion produced a dose-related decrease in MPAP in hypoxia-adapted rats. ANP infusion at doses of 0.2 and $1.0 \mu \mathrm{g} / \mathrm{h}$ reduced MPAP by a mean of 5.9 and $9.3 \mathrm{mmHg}, \sim 17$ and $27 \%$ of the vehicle control level and 35 and $55 \%$ of the hypoxia-induced increment in MPAP, respectively. In contrast, ANP $(0.2 \mu \mathrm{g} / \mathrm{h}) \mathrm{did}$ not lower MPAP in normoxic rats or MSAP in either hypoxic or normoxic rats (Fig. 1, middle). There was no difference in MSAP between the vehicle-treated hypoxic and normoxic groups. Rats exposed to hypoxia for 4 wk had reduced body weight compared to air controls (Fig. 1, bottom) but chronic ANP infusion had no additional effect on body wt. in either normoxic or hypoxic rats.

Chronic ANP infusion significantly reduced $\mathrm{RV} /$ body weight (BW) (Fig. 2, left top) and $\mathrm{RV} / \mathrm{LV}+\mathrm{S}$ (Fig. 2, right top) in a dose-related fashion in hypoxia-adapted rats, indicating that exogenous ANP attenuated the development of hypoxiainduced right ventricular hypertrophy. The percent reduction in $\mathrm{RV} / \mathrm{BW}$ induced by ANP infusion was comparable to the percent decrease in MPAP. In contrast, ANP infusion $(0.2$ $\mu \mathrm{g} / \mathrm{h}$ ) did not significantly alter $\mathrm{RV} / \mathrm{BW}$ in air-control rats. There was no significant difference in $\mathrm{LV}+\mathrm{S} / \mathrm{BW}$ between the vehicle-treated hypoxic and normoxic groups (Fig. 2, left bottom). Chronic ANP infusion produced a statistically insignificant increase in $\mathrm{LV}+\mathrm{S} / \mathrm{BW}$ in both the hypoxia-adapted and air-control rats at a dose of $0.2 \mu \mathrm{g} / \mathrm{h}$ and a significant increase at a dose of $1.0 \mu \mathrm{g} / \mathrm{h}$ in the hypoxic rats. The wall thickness of small pulmonary arteries $(50-100 \mu \mathrm{m}$ diam) was significantly greater in the hypoxic + vehicle group than in air controls (Fig. 2, right bottom). Chronic ANP infusion at both doses significantly decreased the wall thickness of these vessels.

Rats exposed to hypoxia for $4 \mathrm{wk}$ and infused with vehicle had significantly greater (80\% increase) plasma ANP levels than air controls (Fig. 3, top). Hypoxia-adapted animals infused with ANP at the lower dose $(0.2 \mu \mathrm{g} / \mathrm{h})$ had only modest $(60 \%$ of baseline, or $96 \mathrm{pg} / \mathrm{ml})$ elevations in plasma ANP levels compared to vehicle-infused, hypoxic controls after 4 wk of ANP infusion. ANP infusion at the higher dose $(1.0 \mu \mathrm{g} / \mathrm{h})$ produced a 2.3-fold increase in plasma ANP in hypoxiaadapted rats.

The time course study revealed a fivefold elevation in plasma ANP compared to normoxic control levels on day 1 of 

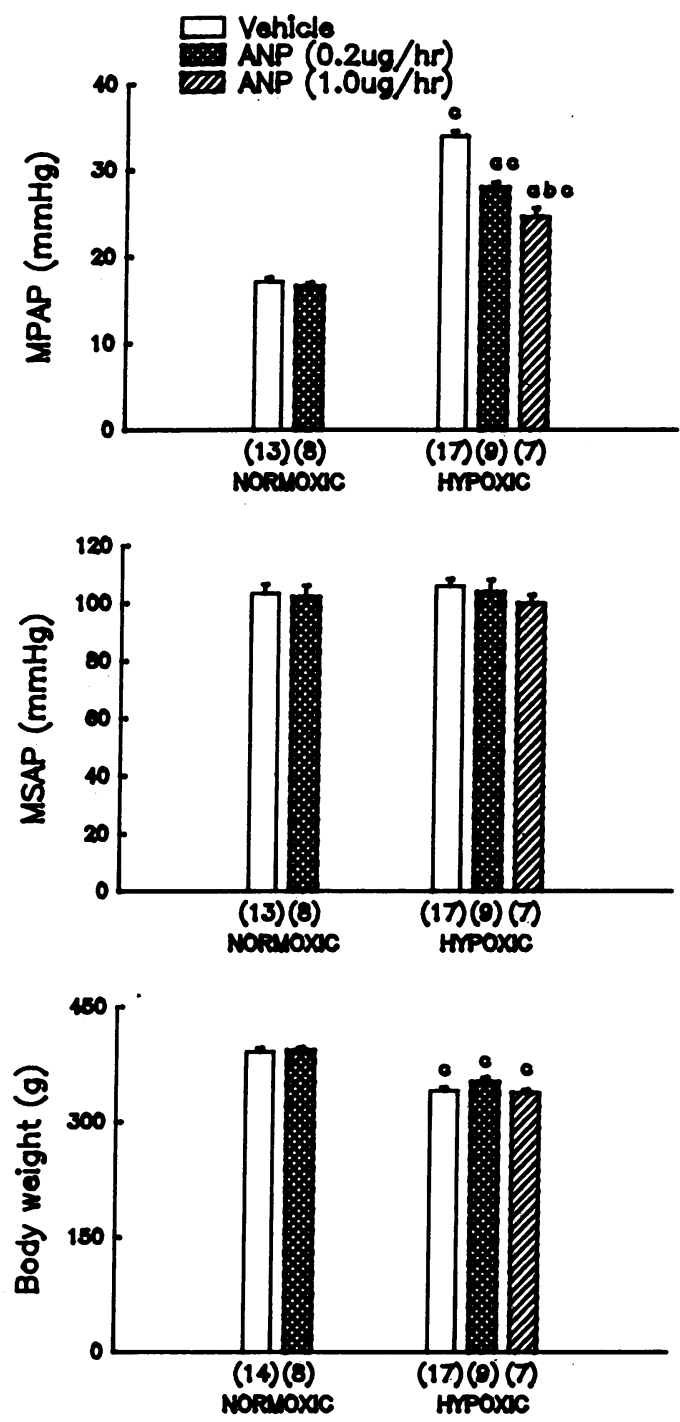

Figure 1. Effect of chronic ANP infusion on MPAP, MSAP, and BW in hypoxia-adapted rats. ${ }^{a} P<0.01$, compared to the respective vehicle group. ${ }^{b} P<0.01$, compared to the hypoxic + ANP $(0.2 \mu \mathrm{g} / \mathrm{h})$ group. ${ }^{c} P<0.01$, compared to the normoxic group. MPAP $=$ mean pulmonary arterial pressure. MSAP $=$ mean systemic arterial pressure. BW, body weight.

infusion (Fig. 3, middle). Plasma ANP fell to $2.5 \times$ control levels on day 3 , plateaued at $\sim 2 \times$ control levels by day 10 , and remained at that level on day 14. Survival of ANP dissolved in $0.1-\mathrm{M}$ acetic acid and incubated at $37^{\circ} \mathrm{C}$ in vitro was $\sim 50 \%$ of starting concentrations at 1-2 wk (Fig. 3, bottom). Further, the mean ANP concentration in the reservoirs of the spent minipumps was $246 \pm 33 \mathrm{ng} / \mathrm{ml}(n=15), \sim 55 \%$ of the initial ANP concentration. This decrement was proportional to the percent decrease in plasma ANP levels between days 1 and 14 of ANP infusion. Thus, hydrolysis of ANP in the pump reservoirs likely accounts for the fall in plasma ANP levels seen during the course of the infusion.

\section{Discussion}

In the current study, chronic infusion of ANP for 4 wk beginning before the initiation of exposure to normobaric hypoxia decreased MPAP, RV/BW, and the ratio $R V / L V+S$ at dose- related fashion compared to values in vehicle-treated hypoxiaadapted rats. ANP infusion was also associated with significant reductions in wall thickness of small (50-100 $\mu \mathrm{m})$ pulmonary arteries, measured in a perfusion-fixed heart-lung preparation. ANP did not alter any of these parameters in air-control rats. The high dose $(1.0 \mu \mathrm{g} / \mathrm{h})$ ANP infusion reduced MPAP from $33.9 \pm 0.6$ to $24.6 \pm 1.0 \mathrm{mmHg}(P<0.01)$; RV/BW from $1.04 \pm 0.02$ to $0.88 \pm 0.03 \mathrm{mg} / \mathrm{g}(P<0.01)$, and pulmonary vascular wall thickness from $22.1 \pm 0.4$ to $19.8 \pm 0.5 \%(P<0.05)$. The low-dose $(0.2 \mu \mathrm{g} / \mathrm{h})$ ANP infusion, which produced only a $60 \%$ elevation in plasma ANP levels compared to vehicle controls, also reduced MPAP, RV/BW, RV/LV+S, and wall thickness of small pulmonary arteries in hypoxia-adapted rats. The reductions in MPAP, $\mathrm{RV} / \mathrm{BW}$, and $\mathrm{RV} / \mathrm{LV}+\mathrm{S}$ were significantly greater with high- than with low-dose ANP; the effect on the pulmonary vessels was not dose-dependent. Chronic ANP infusion did not significantly alter MSAP or body weight in either hypoxia-adapted or air-control rats. These results demonstrate that chronic ANP infusion attenuates the development of chronic hypoxia-induced pulmonary hypertension and right ventricular hypertrophy in a dose-dependent fashion and that increments in circulating ANP levels, which have no systemic depressor effect, attenuate the development of pulmonary hypertension and right ventricular hypertrophy in rats adapted to normobaric hypoxia. This is the first demonstration that chronically elevating circulating ANP levels by infusing exogenous peptide has a biologically important effect on the pulmonary circulation.

Our observation that plasma ANP levels were significantly elevated in vehicle-treated hypoxia-adapted rats compared with air controls confirms previous findings that hypoxia causes ANP release in vivo and in vitro $(5-9,22,23)$. In the current study, chronic hypoxic exposure was associated with an $80 \%$ elevation in endogenous plasma ANP. Chronic infusion of exogenous ANP in doses that produced comparable elevations in plasma ANP levels attenuated the development of pulmonary hypertension and right ventricular hypertrophy in hypoxia-adapted rats. Taken together, the data suggest that endogenous ANP may play a role in the control of pulmonary artery pressure and in the pathogenesis of hypoxia-induced pulmonary hypertension, tending to attenuate the increase in pulmonary artery pressure induced by hypoxic adaptation.

ANP has a direct relaxant effect on pulmonary arterial smooth muscle in vitro $(1,2,24,25)$. Removal of the vascular endothelium does not alter this response, suggesting that it is not dependent on endothelium-derived relaxant factors $(2$, 24). Further, it has been reported that the vasorelaxant effects of ANP in the pulmonary artery are more potent than in the renal artery under the same conditions (2). The relaxant effect of ANP has been found to be 10 times more potent on pulmonary arteries than on renal arteries in isolated vascular preparations from pigs (25).

In vivo studies have documented that intravenous injection or infusion of ANP produces significant blunting of acute hypoxia-induced pulmonary vasoconstriction in rats, cats, dogs, and pigs (7, 13-15). Further, our previous studies demonstrated that bolus injection of ANP in conscious rats produces dose-related decreases in pulmonary artery pressure in both hypoxia-adapted and air-control animals (16). The pulmonary depressor effect of ANP is significantly increased in the hypoxic group compared with the air-control group. Further, we have previously shown that ANP lowers pulmonary 

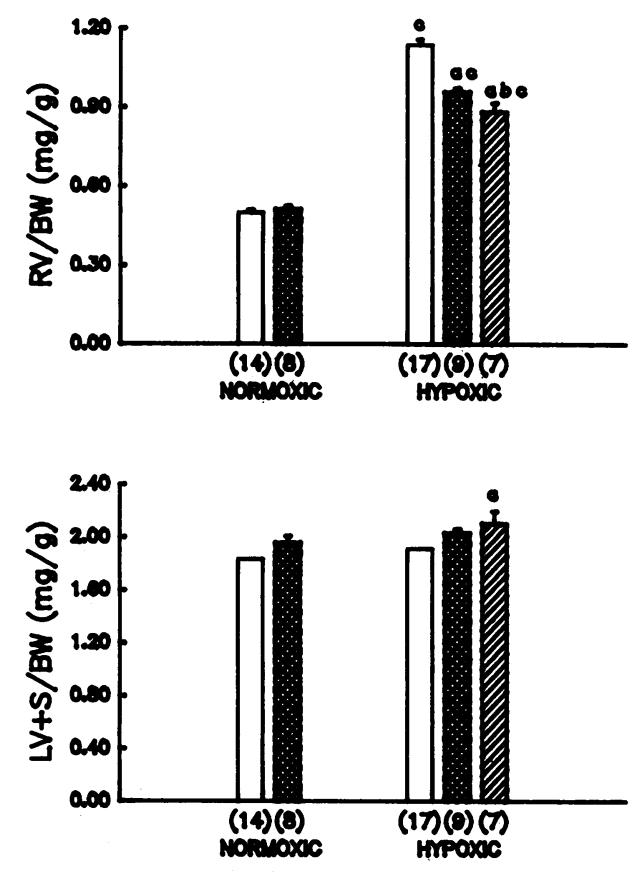
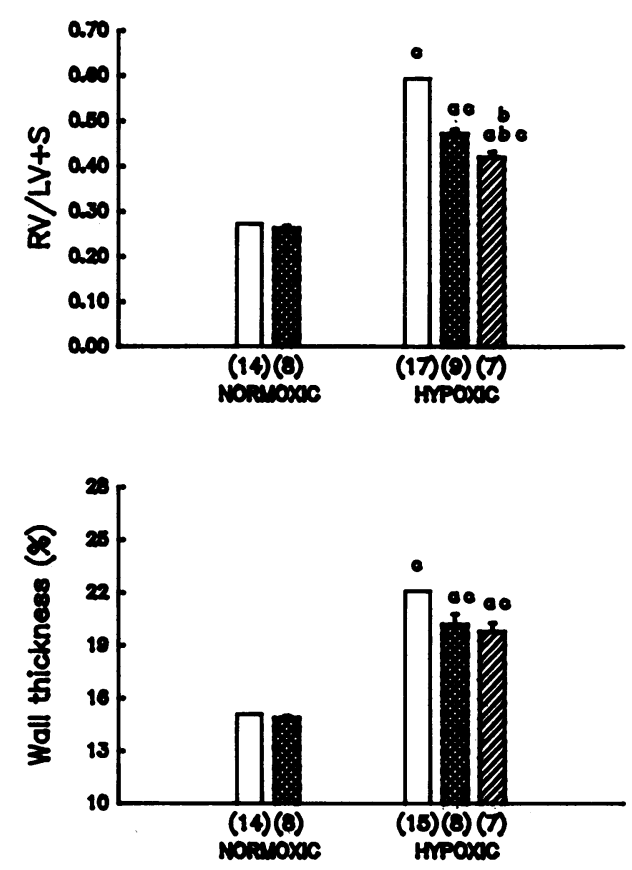

Figure 2. Effect of chronic ANP infusion on $\mathrm{RV} / \mathrm{BW}, \mathrm{RV} / \mathrm{LV}+\mathrm{S}$, $\mathrm{LV}+\mathrm{S} / \mathrm{BW}$, and wall thickness of small (50-100 $\mu \mathrm{m})$ pulmonary vessels in hypoxiaadapted rats. ${ }^{a} P<0.01$, compared to the respective vehicle group. ${ }^{b} P$ $<0.05$, compared to the hypoxic + ANP $(0.2$ $\mu \mathrm{g} / \mathrm{h})$ group. ${ }^{c} P<0.01$, compared to the normoxic group. RV, weight of right ventricle free wall. BW, body weight. $L V+S$, weight of left ventricle and septum. artery pressure significantly in isolated lungs from both hypoxia-adapted and air-control rats, and that this effect is significantly greater in the hypoxic than the air-control lungs. These findings suggest that ANP lowers pulmonary artery pressure in rats with hypoxia-induced pulmonary hypertension mainly by a direct vasodilator effect on the pulmonary vasculature (16). In addition, a recent clinical study has shown that incremental infusion rates of ANP in patients with pulmonary hypertension secondary to chronic obstructive lung disease causes dose-dependent vasodilation in the pulmonary circulation (26). After ANP infusion at the highest dose tested $(0.1 \mu \mathrm{g} / \mathrm{kg}$ per min), pulmonary vascular resistance fell by $37 \%$. Together with the current findings, these data raise the possibility that ANP may be useful in the treatment and prevention of hypoxic pulmonary hypertension in man.

ANP induces significant decreases in cardiac output in conscious and anesthetized rats and dogs (27-31). Most investigators believe that this fall in cardiac output is due to a reduction in venous return rather than a direct cardiac depressant action of ANP $(31,32)$. The mechanism by which ANP reduces venous return is uncertain and controversial. ANP has been reported to induce venodilation (28), leading to an augmentation of venous capacitance (31). In contrast, other observations suggest that ANP may increase resistance to venous return $(29,33,34)$ via passive and active venoconstriction (34). In addition, ANP decreases plasma volume by shifting volume from the intravascular to the interstitial compartment (35). This may, in part, account for the ANP-induced reduction in venous return. The reduction in cardiac output could provide an additional mechanism for the pulmonary depressor effect of ANP in the hypoxia-adapted rat. However, recent studies have called into question the importance of the ANPinduced reduction in cardiac output in lowering pulmonary artery pressure in animals with hypoxic pulmonary hypertension. ANP infusion in doses that did not affect cardiac output markedly lowered pulmonary artery pressure and pulmonary vascular resistance in pigs exposed to acute hypoxia, indicating that the pulmonary depressor response to ANP in this model is not due to a reduction in cardiac output (7). Further, our previous studies demonstrated that MSAP, MPAP, and cardiac output fell immediately after bolus injection of ANP in both hypoxia-adapted and air-control rats, whereas cardiac output in hypoxia-adapted rats was not different from that in weight-matched air controls. The reduction in MPAP was three times as great in hypoxia-adapted rats as in air controls (16). These findings suggest that the enhanced pulmonary depressor effect of ANP in hypoxia-adapted rats was not secondary to the reduction in cardiac output.

Alveolar hypoxia is a potent constrictor of pulmonary blood vessels (36), and exposure to chronic hypoxia causes smooth muscle cell growth and wall thickening in small peripheral pulmonary arteries $(18,37)$. Thus, the pulmonary hypertension and secondary RV hypertrophy observed in hypoxia-adapted rats in the current study likely resulted from both functional constriction and anatomic wall thickening of the pulmonary vasculature. We observed that 4-wk exposure to normobaric hypoxia led to doubling of MPAP and a 1.3-fold increase in $\mathrm{RV} / \mathrm{BW}$, respectively, but only a $46 \%$ increase in the wall thickness of small $(50-100 \mu \mathrm{m})$ pulmonary arteries in a perfusion-fixed lung preparation, in which increased wall thickness reflects mainly morphological wall thickening, rather than active pulmonary vasoconstriction. Chronic ANP infusion at a dose of $1.0 \mu \mathrm{g} / \mathrm{h}$ reduced MPAP and $R V / B W$ by 27 and $22 \%$, respectively, but reduced the wall thickness of small $(50-100 \mu \mathrm{m})$ pulmonary arteries by only $10 \%$ in the hypoxia-adapted rats; ANP had no effect on any of these parameters in air-control rats. It is likely that ANP lowered MPAP and RV/BW by attenuating both active vasoconstriction and morphological wall thickening of pulmonary vessels in hypoxia-adapted rats, whereas the ANP-induced reductions in pulmonary vascular wall thickness reflect decrements in morphological wall thickening only. This interpretation might 

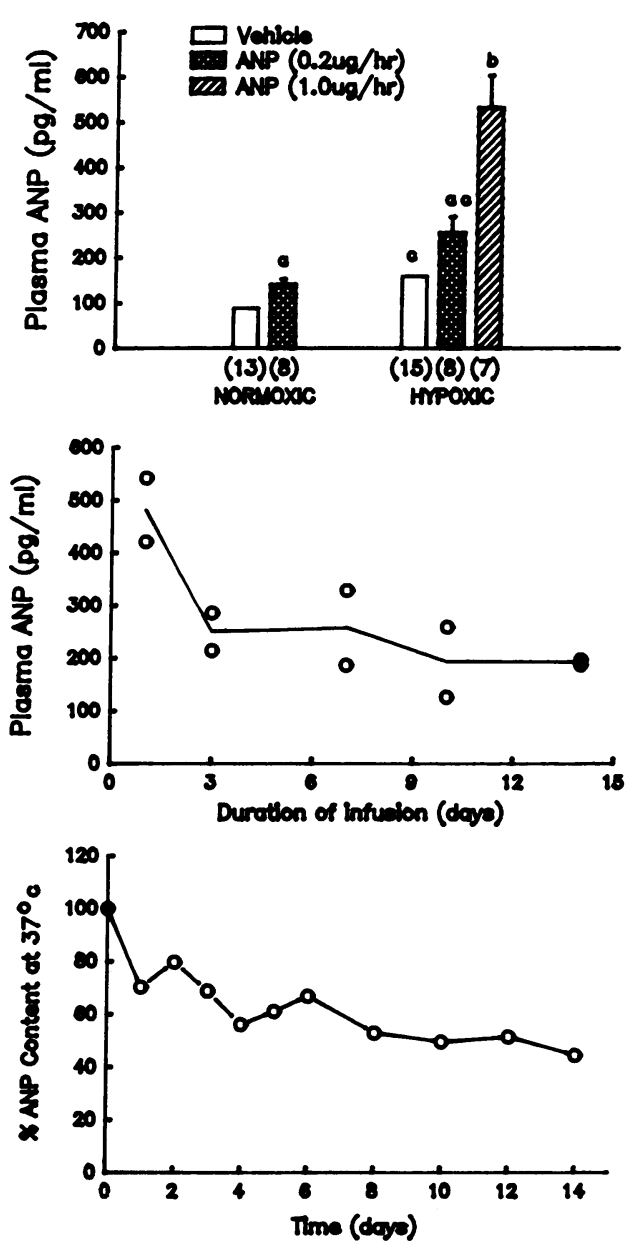

Figure 3. (Top) Effect of chronic ANP infusion on plasma ANP levels. ${ }^{a} P<0.05$, compared to the respective vehicle group. ${ }^{b} P$ $<0.01$, compared to each of the other groups. ${ }^{c} P<0.05$, compared to the respective normoxic group. (Middle) Time course of plasma ANP levels after chronic ANP infusion $(0.2 \mu \mathrm{g} / \mathrm{h})$ in two conscious air-control rats. $O$ represents the value of each rat. - represents the mean value of two rats. (Bottom) Time course of \% ANP content in $0.1 \mathrm{M}$ acetic acid at $37^{\circ} \mathrm{C}$.

also account for the absence of a dose-related effect of exogenous ANP on pulmonary vascular wall thickness in these experiments.

The hypoxia-adapted rats treated with ANP at the higher dose $(1.0 \mu \mathrm{g} / \mathrm{h})$ showed a significant increase in $\mathrm{LV} / \mathrm{BW}$ compared with the vehicle-treated hypoxic group, whereas LV/BW in both normoxic and hypoxic rats treated with lower-dose ANP showed a nonsignificant tendency to increase compared with vehicle controls. ANP administration has been reported to produce an increase in peripheral vascular resistance in conscious rats and sheep $(28,38)$, possibly as a reflex response to decreased cardiac output. This increase in peripheral vascular resistance would be expected to increase left ventricular workload, resulting in left ventricular hypertrophy. Since we have previously demonstrated that ANP infusion significantly decreases cardiac output in both hypoxia-adapted and aircontrol rats (16), this mechanism could likely account for the increase in LV weight observed after ANP infusion in the current study.
In summary, the current study demonstrated that chronic ANP infusion in a dose which produced only a modest elevation in plasma ANP levels attenuated the development of pulmonary hypertension and right ventricular hypertrophy and decreased the wall thickness of small (50-100 $\mu \mathrm{m})$ pulmonary arteries in hypoxia-adapted rats. ANP had none of these effects in normoxic-control rats. Adaptation to chronic hypoxia for 4 wk was associated with an elevation in endogenous plasma ANP comparable in magnitude to that seen with the low-dose chronic ANP infusions. Further, infusion of ANP at a higher dose caused enhanced reductions in pulmonary artery pressure and right ventricular weight but no added effect on pulmonary arterial wall thickness. The data suggest that ANP may be involved in the regulation of pulmonary vascular tone in rats adapted to chronic hypoxia.

\section{Acknowledgments}

The excellent technical assistance of Joan Durand and editorial assistance of Charlane Crouse are gratefully acknowledged. We would also like to thank Wyeth Laboratories for providing the anti-ANP antibody.

This work was supported in part by research grants from the American Lung Association, the Council for Tobacco Research, USA, Inc. the Veterans Administration (VA) and NIH-NHLBI HL-39147, HL-22544, and HL-35051 (Specialized Center of Research in Hypertension). Dr. R. Jackson received an E. L. Trudeau Fellowship from the American Lung Association, and a Career Development Award from the VA Research Service.

\section{References}

1. Chou, J., E. Kubota, T. Sata, and S. I. Said. 1986. Comparative relaxant activities of atrial natriuretic peptide (ANPs) and vasoactive intestinal peptide (VIP) on smooth muscle structures in lung. Fed. Proc. 45:553. (Abstr.)

2. Morice, A. H., T. L. Jansen, and M. J. Brown. 1987. The effect of atrial natriuretic factors on in vitro pulmonary artery pressure. $\mathrm{Am}$. Rev. Respir. Dis. 135:A300. (Abstr.)

3. Sakamoto, M., K. Nakao, N. Morii, A. Sugawara, T. Yamada, H. Itoh, S. Shiono, Y. Satio, and H. Imura. 1986. The lung as a possible target organ for atrial natriuretic polypeptide secreted from the heart. Biochem. Biophys. Res. Commun. 135:515-520.

4. Sardella, G., S. Yen, and L. C. Ou. 1987. Further evidence for an important role of the atrial natriuretic factor (ANF) in pulmonary circulation. Fed. Proc. 46:518. (Abstr.)

5. Baertschi, A. J., J. M. Adams, and R. Pence. 1987. Hypoxia as a physiological stimulus for the secretion of atrial natriuretic factor (ANF)—a new hypothesis. Fed. Proc. 46:647. (Abstr.)

6. Baertschi, A. J., C. Hausmaninger, R. S. Walsh, R. M. Mentzer, D. A. Wyatt, and R. A. Pence. 1986. Hypoxia-induced release of atrial natriuretic factor (ANF) from the isolated rat and rabbit heart. Biochem. Biophys. Res. Commun. 140:427-433.

7. Adnot, S., P. E. Chabrier, C. Brun-Buisson, I. Viossat, and P. Braquet. 1988. Atrial natriuretic factor attenuates the pulmonary pressor response to hypoxia. J. Appl. Physiol. 65:1975-1983.

8. McKenzie, J. C., I. Tanaka, T. Inagami, K. S. Misono, and R. M. Klein. 1986. Alterations in atrial and plasma atrial natriuretic factor (ANF) content during development of hypoxia-induced pulmonary hypertension in the rat. Proc. Soc. Exp. Biol. Med. 181:459-463.

9. Brun-Buisson, C., Y. Gutkowska, and P. Braquet. 1987. Atrial natriuretic peptide concentrations and pulmonary hemodynamics in patients with pulmonary artery hypertension. Am. Rev. Respir. Dis. 136:951-956.

10. Olins, G. M., D. R. Pattron, F. S. Tjoeng, and D. J. Blehm. 
1986. Specific receptors for atriopeptin III in rabbit lung. Biochem. Biophys. Res. Commun. 140:302-307.

11. Bianchi, C., J. Gutkowska, G. Thibault, R. Garcia, J. Genest, and M. Cantin. 1986. Radioautographic localization of 125-I-atrial natriuretic factor (ANF) in rat tissue. Histochemistry. 82:441-452.

12. Weselcouch, E. O., W. R. Humphrey, and J. W. Aiken. Effect of pulmonary and renal circulations on activity of atrial natriuretic peptide. 1985. Am. J. Physiol. 249:R595-R602.

13. Ou, L. C., G. L. Sardella, and N. S. Hill. 1987. Pulmonary and systemic hemodynamic and diuretic effects of atrial natriuretic factor (ANF) in chronically instrumented rats. Fed. Proc. 46:518. (Abstr.)

14. Tadepalli, A. S., and A. D. Krueger. 1987. Effect of systemic human atrial natriuretic peptide (ANP) on hypoxic pulmonary vasoconstriction. Fed. Proc. 46:518. (Abstr.)

15. Will, D. H., and M. A. Council. 1986. Atriopeptin III: a pulmonary vasodilator in experimental hypoxic pulmonary hypertension. Fed. Proc. 45:556. (Abstr.)

16. Jin, H., R. H. Yang, Y. F. Chen, R. M. Thornton, R. Jackson, and S. Oparil. 1988. Atrial natriuretic peptide lowers pulmonary arterial pressure in hypoxia adapted rats. J. Appl. Physiol. 65:1729-1735.

17. Jin, H., R. H. Yang, Y. F. Chen, R. Jackson, and S. Oparil. 1987. Arginine vasopressin lowers pulmonary arterial pressure in rats adapted to chronic hypoxia. Am. J. Med. Sci. 30:274-278.

18. Rabinovitch, M., W. Gamble, A. S. Nadas, O. S. Miettines, and L. Reid. 1979. Rat pulmonary circulation after chronic hypoxia: hemodynamics and structural features. Am. J. Physiol. 5:H818-H827.

19. Tanaka, I., K. S. Misono, and T. Inagami. 1984. Atrial natriuretic factor in rat hypothalamus, atria and plasma: determination by specific radioimmunoassay. Biochem. Biophys. Res. Commun. 124:663-667.

20. Eskay, R., Z. Zukowska-Grojec, M. Haass, J. R. Dave, and N. Zamir. 1986. Circulating atrial natriuretic peptides in conscious rats: regulation of release by multiple factors. Science (Wash. DC). 232:636-639.

21. Larose, P., S. Meloche, P. du Souich, A. Delean, and H. Ong. 1985. Radioimmunoassay of atrial natriuretic factor: human plasma levels. Biochem. Biophys. Res. Commun. 130:553-558.

22. Jin, H., Y. F. Chen, R. H. Yang, R. Jackson, and S. Oparil. 1988. Arginine vasopressin induces exaggerated release of atrial natriuretic peptide in conscious rats adapted to chronic hypoxia. Clin. Res. 36:44a. (Abstr.)

23. Stockmann, P. T., D. H. Will, S. D. Sides, S. R. Brunnert, G. D. Wilner, K. M. Leahy, R. C. Wiegand, and P. Needleman. 1988. Reversible induction of right ventricular atriopeptin synthesis in hypertrophy due to hypoxia. Circ. Res. 63:207-213.

24. Ignarro, L. J., K. S. Wood, R. G. Harbison, and P. J. Kadowitz. 1986. Atriopeptin II relaxes and elevates cGMP in bovine pulmonary artery but not in vein. J. Appl. Physiol. 60:1128-1133.
25. Jansen, T. L. Th. A., A. H. Morice, and M. J. Brown. 1987. A comparison of the vasodilator responses to atrial peptides in the pulmonary and renal arteries of the pig in vitro. Br. J. Pharmacol. 91:687-691.

26. Adnot, S., A. Andrivet, P. E. Chabrier, J. Piquet, P. Braquet, and C. Brun-Buisson. 1988. Atrial natriuretic factor (ANF) in chronic hypoxic pulmonary hypertension-physiological correlates and responses to peptide infusion. Am. J. Hypertension. 1:100A. (Abstr.)

27. Kleinhert, H. D., M. Volpe, G. Odell, D. Marion, S. A. Atlas, M. J. F. Camargo, J. H. Laragh, and T. Maack. 1986. Cardiovascular effects of synthetic atrial natriuretic factor in anesthetized and conscious dogs. Hypertension (Dallas). 8:312-316.

28. Lappe, R. W., J. F. M. Smits, J. A. Todt, J. J. M. Debets, and R. L. Wendt. 1985. Failure of atriopeptin II to a cause arterial vasodilation in the conscious rat. Circ. Res. 56:606-612.

29. Pegram, B. L., N. C. Trippodo, T. Natsume, M. B. Kardon, E. D. Frohlich, F. E. Cole, and A. A. MacPhee. 1986. Hemodynamic effects of atrial natriuretic hormone. Fed. Proc. 45:2382-2386.

30. Volpe, M., E. Sosa, F. B. Mueller, M. J. F. Camargo, N. Glorioso, J. H. Laragh, T. Maack, and S. A. Atlas. 1986. Differing hemodynamic responses to atrial natriuretic factor in two models of hypertension. Am. J. Physiol. 250:H871-878.

31. Zimmerman, R., J. A. Schirgen, B. S. Edwards, T. R. Schwab, D. M. Heublein, J. C. Burnett, Jr. 1987. Cardio-renal-endocrine dynamics during stepwise infusion of physiologic and pharmacologic concentrations of atrial natriuretic factor in the dog. Circ. Res. 60:662-669.

32. Lang, R. E., T. Unger, and D. Ganten. 1987. Atrial natriuretic peptide: a new factor in blood pressure control. J. Hypertens. 5:255271.

33. Chien, Y. W., E. D. Frohlich, and N. C. Trippodo. 1986. Atrial natriuretic peptide increases resistance to venous return in rats. $\mathrm{Am}$. J. Physiol. 252:H894-H899.

34. Trippodo, N. C., F. E. Cole, E. D. Frohlich, and A. A. MacPhee. 1986. Atrial natriuretic peptide decreases circulating capacitance in areflexic rats. Circ. Res. 59:291-296.

35. Almeida, F. A., M. Suzuki, and T. Maack. 1986. Atrial natriuretic factor increases hematocrit and decreases plasma volume in nephrectomized rats. Life Sci. 39:1193-1199.

36. Slonim, N. B., and L. Y. Hamilton. 1987. Respiratory Physiology. 5th ed. C. V. Mosby Co., St. Louis, MO. 120 pp.

37. Abraham, A. S., J. M. Kay, R. B. Cole, and A. C. Pincock. 1971. Haemodynamic and pathological study of the effect of chronic hypoxia and subsequent recovery of the heart and pulmonary vasculature of the rat. Cardiovasc. Res. 5:95-102.

38. Breuhaus, B. A., H. H. Saneii, M. A. Brandt, and J. E. Chimoskey. 1985. Atriopeptin II lowers cardiac output in conscious sheep. Am. J. Physiol. 249:R776-R780. 